\title{
Preparation and Usage of Polyaluminum Chloride as a Coagulating Agent
}

\author{
SK Al-Dawery*a and OH Al-Jouborib \\ *a Department of Chemical Engineering, University of Nizwa, Sultanate of Oman \\ ${ }^{b}$ Department of Chemical Engineering, University of Baghdad, Iraq
}

Received 5 January 2010; accepted 13 December 2010

\begin{abstract}
Three different coagulating agents, Iraqi-produced alum, Swedish-produced alum, and laboratory-produced polyaluminum chloride (PAC) were used to clarify samples taken from Iraqi river water. A laboratory rig was built to produce PAC from the reaction between hydrochloric acid and aluminum powder. The results after raw water treatment showed that the dosage of PAC required for treatment was $98 \%$ less than that of alum when it was applied to water at a low turbidity and almost $90 \%$ less in the case of much higher turbidity. The application of PAC produced rapidly forming flocs and more compact sludge compared to that of alum. However, there were no significant changes in the $\mathrm{pH}$ of the solution. From the results obtained, the PAC agent performed better compared to alum and might be considered a good alternative to alum for raw water and waste water treatment.
\end{abstract}

Keywords: Alum, Polyaluminum chloride, Water treatment

$$
\begin{aligned}
& \text { تحضير واستخدام مادة بولي كلوريد الألمنيوم كمادة مخثرة في تصفية المياه }
\end{aligned}
$$

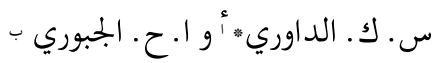

$$
\begin{aligned}
& \text { الملخص: يهدف البحث إلى دراسة استخدام بولي كلوريد الألمنيوم كمادة بديلة عن مادة الشب المستخدمة كمادة مخثرة في مشاريع تصفية المياه في }
\end{aligned}
$$

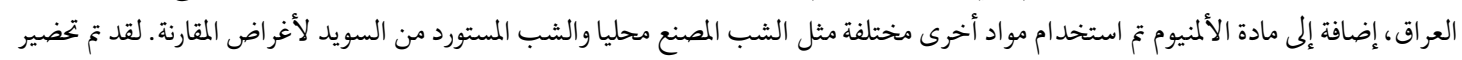

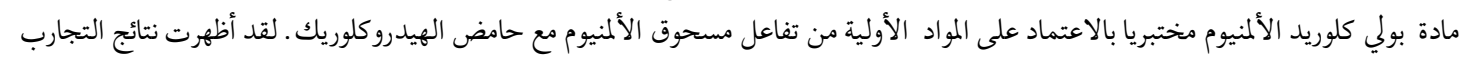

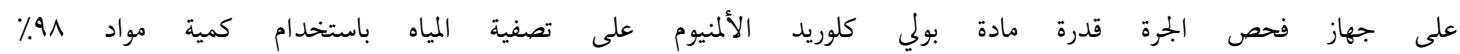

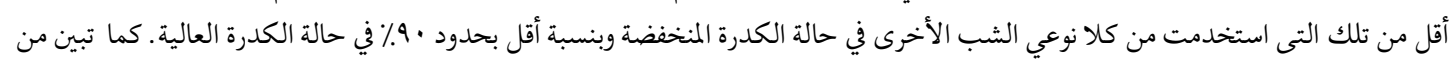

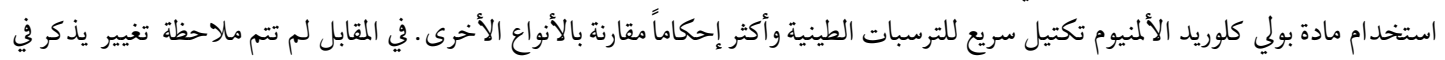

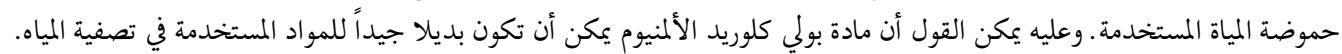

$$
\begin{aligned}
& \text { الكلمات الدالة: الشب، بولى كلوريد اللالمنيوم، معالجة المياه. }
\end{aligned}
$$

\section{Introduction}

Water generally contains suspended and colloidal solids from land erosion, decaying, vegetation, microorganisms, and color-producing compounds. Coarser materials such as sand and silt can be eliminated to a considerable extent by plain sedimentation, but finer particles, such as those between 1-100 mm, must be chemically coagulated to produce larger flocs which are removable in subsequent settling and filtration (Mark 1975).

In considering the aggregation of particles in a colloidal dispersion, it is useful to distinguish between two distinct steps:
(1) particle transport to affect particle contacts, and

(2) particle destabilization to permit attachment when contact occurs.

Particle transport in an aqueous systems is essentially a physical process, which is accomplished by Brownian diffusion, fluid motion, and sedimentation. It can be controlled by physical parameters such as temperature, velocity gradient, and particle size. Particle destabilization is clearly a colloidal - chemical process which can be controlled by both chemical and physical parameters (Stumm, Charles 1968). There are many substances which react suitably with water to

*Corresponding author's e-mail: salam@unizwa.edu.om 
produce such an effect, known collectively as coagulants. The precipitate so formed in the water is called the floc. The larger and heavier the floc is, the quicker the rate of settlement (George 1988). Commonly used coagulants in water treatment are:

1. Coagulats based on aluminum, such as aluminum sulfate $\left(\mathrm{Al}_{2}\left(\mathrm{SO}_{4}\right)_{3} \cdot 18 \mathrm{H}_{2} \mathrm{O}\right)$, sodium aluminates $\left(\mathrm{Na}_{3} \mathrm{AlO}_{3}\right)$, poly aluminum chloride $\left[\mathrm{Al}_{2}(\mathrm{OH})_{\mathrm{x}} \mathrm{Cl}_{6-\mathrm{x}}\right]_{\mathrm{n}}$, potash aluminum $\left(\mathrm{AlK}\left(\mathrm{SO}_{4}\right)_{2}\right.$. $\left.12 \mathrm{H}_{2} \mathrm{O}\right)$, and ammonia aluminum $\left(\mathrm{AlNH}_{4}\left(\mathrm{SO}_{4}\right)_{2}\right.$. $12 \mathrm{H}_{2} \mathrm{O}$ ),

2. Coagulats based on iron, such as ferric sulfate $\left(\mathrm{FeSO}_{4} \cdot 7 \mathrm{H}_{2} \mathrm{O}\right)$, chlorinated copperas, and ferric chloride $\left(\mathrm{FeCl}_{3}\right)$, and

3. Polyelectrolytes, which are long-chain synthetic polymers with a high molecular weight. These organic chemicals are commercially available under a wide variety of trade names (Mark 1975).

Generally, the type of coagulants and aids available are defined by the plant process scheme and of course, dosages of these substances can be regulated to meet changes in raw water quality. Also, mechanical mixing can be adjusted by varying the speed of the flocculator paddles.

Jar tests are widely used to determine optimum chemical dosages for treatment. This laboratory test attempts to simulate the full-scale coagulation-flocculation process and can be conducted for a wide range of conditions. The interpretation of test results involves visual and chemical testing of the clarified water.

PAC has been found by others to be an acceptable alternative flocculating and coagulating agent for drinking water, waste water, and industrial water treatment (ClearTech Inc. 2008; Alhadidi et al. 2009). Halvadiya et al. (2008) used PAC to clarify turbid lake water, in their work, and found that the required dosage of PAC was $60 \%$ less than that of alum. Many companies, such as Prakash Chemical Agencies Private of India and the Qikang Company of China manufacture PAC for water treatment using different types of raw materials.

The purposes of this work are as follows:

1- Experimental testing: Since locally produced alum is highly impure and many operating problems can occur in its production (Al-Dawery, Butris 2002), PAC is considered an alternative coagulant and has to be tested experimentally.

2- Product comparison: The intent of this work was also perform a comparison between PAC and other types of coagulants such as Iraqi and Swedish produced alums.

3- Waste aluminum use: To test the efficacy of makings use of waste aluminum powder from an aluminum plant to produce PAC on a laboratory scale based on the reaction between aluminum powder and hydrochloric acid.

\section{Experimental Work}

\subsection{Material Preparation}

\subsubsection{Alum Preparation}

As stated above, two types of alums, Swedish produced alum (consisting of $9.63 \% \mathrm{Al}_{2} \mathrm{O}_{3}$ ) and Iraqi produced alum (consisting of $9.28 \% \mathrm{Al}_{2} \mathrm{O}_{3}$ ) were used for comparison. For raw water treatment, an alum solution was required. For such, a 1\% alum solution was prepared by dissolving 10 grams of crystal alum in 1 liter of distilled water.

\subsubsection{Polyaluminum Chloride Production}

Poly aluminum chloride was produced at the laboratory by dissolving 2.7 grams of aluminum powder $(99.9 \%)$ in $100 \mathrm{ml}$ of boiled hydrochloric acid solution of $0.1 \mathrm{~N}$. The total normality of the reactant solution would be around $1 \mathrm{~N}$ (Kohlschutter et al. 1942; Alcoa World Chemicals 2001).

The hydrochloric acid solution and aluminum powder were placed in a two-neck $250 \mathrm{ml}$ flask of as shown in Fig. (1). A temperature thermometer was placed in one neck while the other neck was connected to a glass condenser in order to reduce loss of $\mathrm{HCl}$ through vaporization. The flask was heated via hot metal equipped with a temperature regulator in order to bring the reaction to a suitable operating heat level, and the temperature was then adjusted to $80^{\circ} \mathrm{C}$.

The reaction time was considered to be the time at which the sample's dark color disappeared, the solution become transparent, and all HCL vapor had been removed. The determined time was 5 hours. After the reaction, the sample was drawn and analyzed. The results showed that the specific gravity of the product was 1.078 and, therefore, the net weight of the sample was $97 \mathrm{~g}$ ( 7 grams of salt and 90 grams of water). The laboratory analysis of the produced PAC is presented in Table 1.

\subsection{Turbidity Test}

Turbidity level was considered the criterion index for water clarity. Thus, conventional jar testing equipment was used for this purpose. Before testing, samples of untreated raw water were collected from different sites along the Tigres River and yielded different levels of turbidity such as 30, 150, 550 and 800 floriz- 


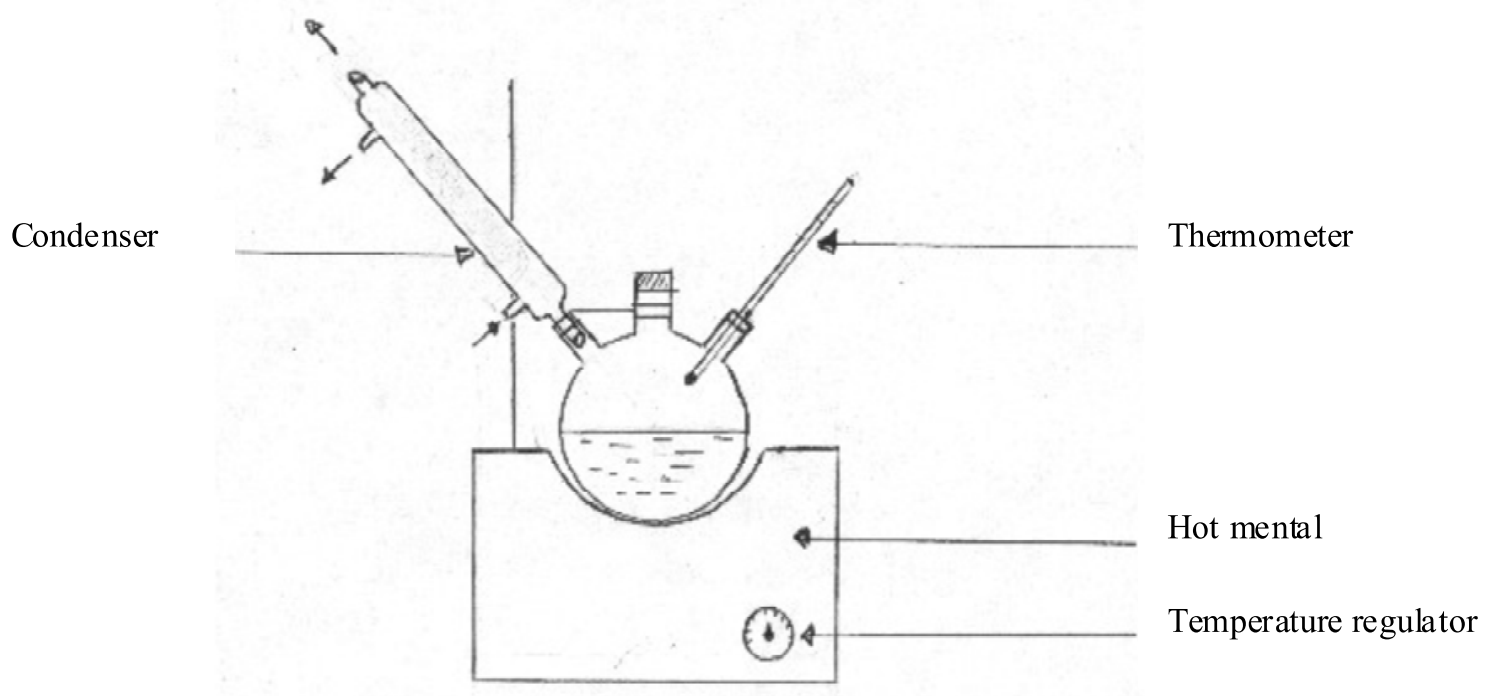

Figure 1. Laboratory apparatus for PAC production

Table 1. Laboratory analysis of the PAC product

\begin{tabular}{ll}
\hline $\mathrm{Al}_{2} \mathrm{O}_{3}$ content & $5.29 \%$ \\
\hline $\mathrm{pH}$ & 4.1 \\
Basicity $\%$ & $30 \%$ \\
Specific gravity & 1.07788 \\
Residual volume & $90 \mathrm{ml}$ \\
\hline
\end{tabular}

ing turbidity units (FTU). Each water sample was treated separately with different types of coagulating agents.

After treatment, residual turbidity of clear water layer was tested at a chosen sedimentation time such as at $0,10,20$ and 30 minutes.

\section{$2.3 \mathrm{pH}$ Test}

Testing of the river water's $\mathrm{pH}$ was undertaken before and after water treatment with all three types of coagulants, but there were no significant changes in the resultant $\mathrm{pH}$. Thus, the effect of the coagulating agents, especially the PAC, on the $\mathrm{pH}$ of the treated water was tabulated. However, $\mathrm{pH}$ of the raw water was 8.4.

\section{Results and Discussion}

This section presents the results of testing the performance of different types of coagulants on the clarity of river water samples at different levels of turbidity. The effects of increasing doses of coagulants (Iraqi produced alum, Swedish produced alum and PAC) on water samples were determined and shown in Figs. 2-5. These figures show the increased removal of water impurities with an increase in the dose of all types of agents. However, the PAC produced the lowest water impurities. Coupled with a low range of dosing, the PAC produced better results than either of the alum coagulats.

By considering a turbidity level of 16 FTU as an index for clear water, the required dosage concentrations of coagulating agents for achieving this level of turbidity were determined and presented in Table 2 . These data show that the dosage of PAC required for raw water treatment was $98 \%$ less than alum at low water impurities $(\mathrm{FTU}=30)$, and required 90\% less agent at higher levels of impurities $(\mathrm{FTU}=800)$. However, other researchers have stated that the PAC required for water treatment is $60 \%$ less as compared to alum (Halvadiya et al. 2008).

During the experiment, it was noted that during the PAC treatment flocs formed rapidly and the sludge produced was more compact than that of the alum. This could be due to the great ease of PAC hydrolysis as compared to that of alum. PAC emits polyhydroxides with long molecular chains and great electrical charges in the solution, thus maximizing the physical action of flocculation. The coagulation can then be carried out by neutralizing the negative charges on colloids by the ionic sites and then causing a decrease in zeta potential without changing the $\mathrm{pH}$ or alkalinity of water.

Also, it was noted that the alum concentration needed for water treatment at turbidity (i.e., 89 $\mathrm{mg} / \mathrm{liter}$ at $\mathrm{FTU}=800$ ) is much higher than that required for treatment at a lower turbidity (i.e., 16 $\mathrm{mg} /$ litre at FTU=30). This can be explained by the additional charge from colloidal suspended solids, and therefore, the high ionic heaviness of the from alum 


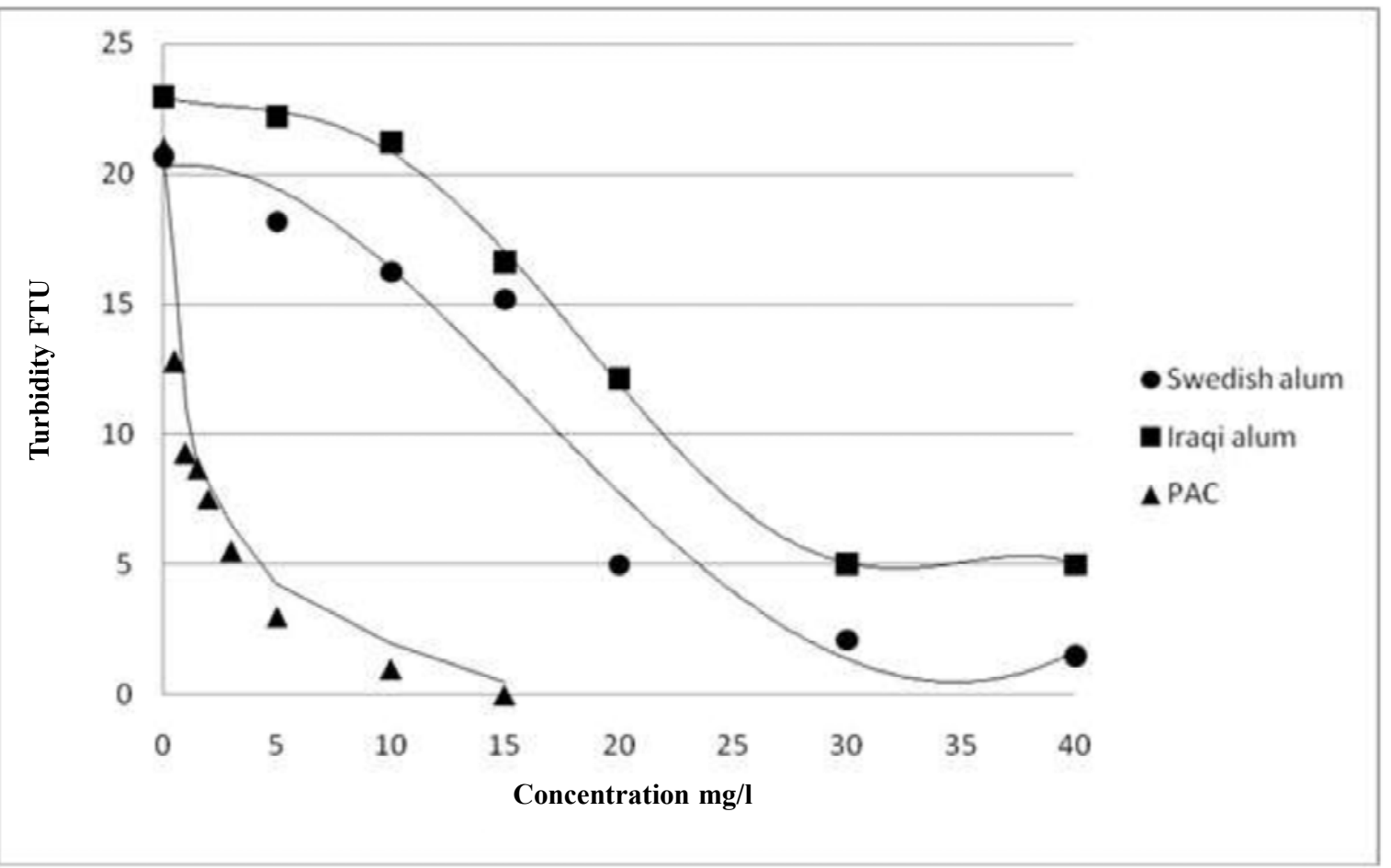

Figure 2. Relation between residual turbidity and coagulat concentration at a 30 FTU level

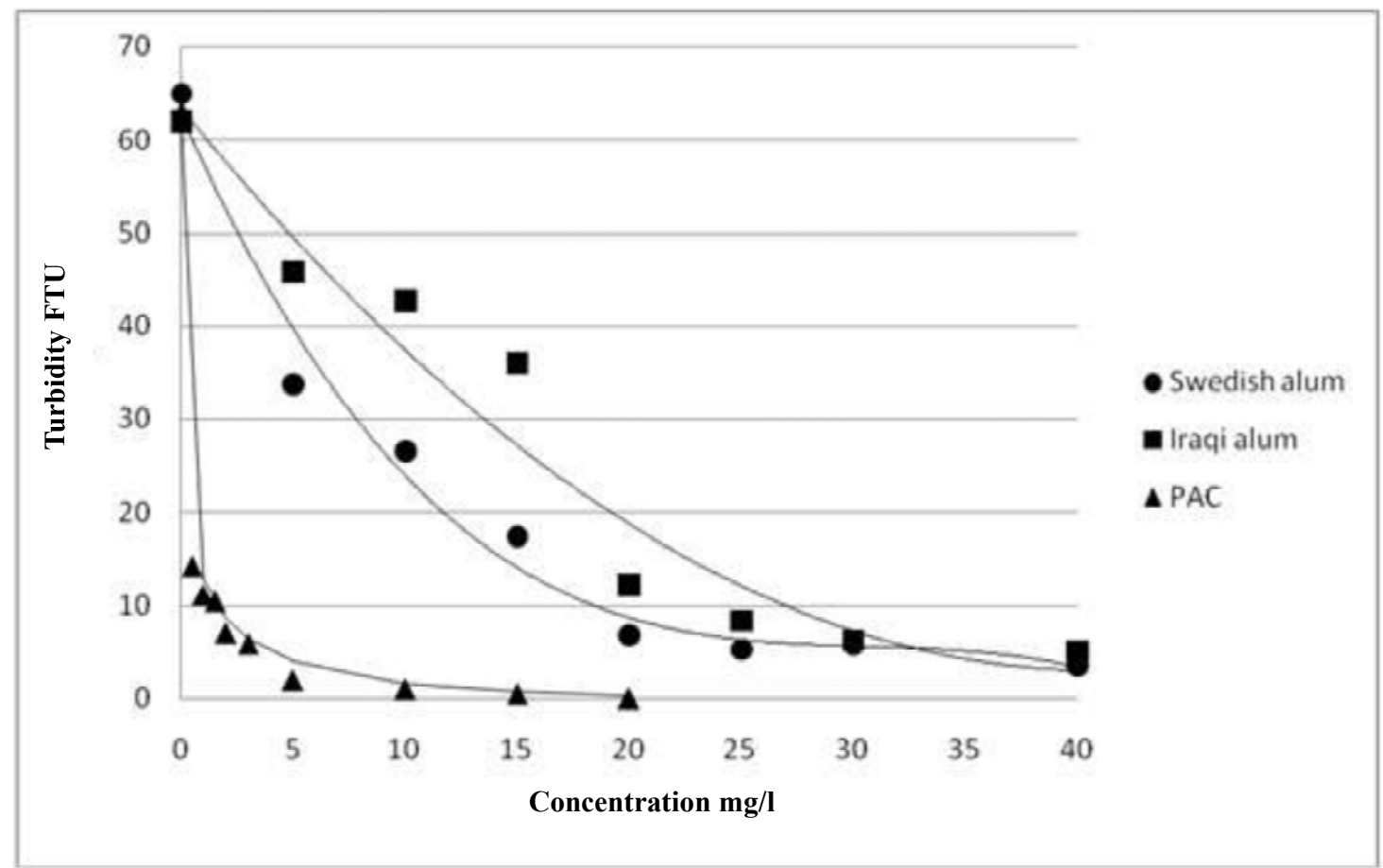

Figure 3. Relation between residual turbidity and coagulat conentration at a 150 FTU level

coagulant was required to overcome these forces, enhance van der Waals force and decrease zeta potential.

However, lower dosages of PAC were required for all turbidity levels. This could be due to the fact that
PAC has a higher hydrolysis characteristic than other alums, which may lead to the enhancement of adsorption of the present coordinated hydroxide group. Simple hydroxide ions may bind strongly to many solid surfaces. Alternatively, the replacement of an 
Preparation and Usage of Poly Aluminum Chloride as a Coagulant Agent

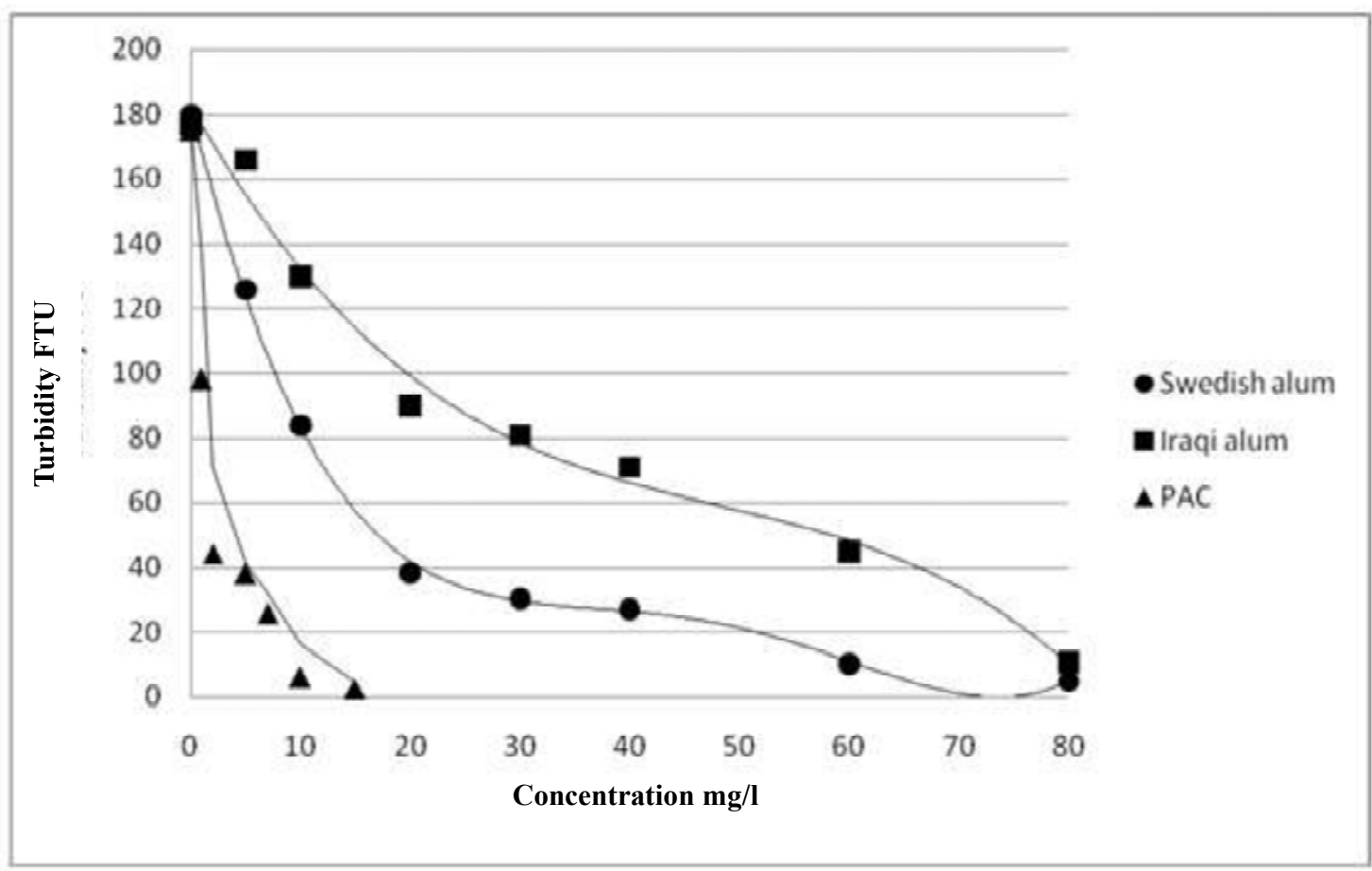

Figure 4. Relation between residual turbidity and coagulant concentration at 550 FTU level

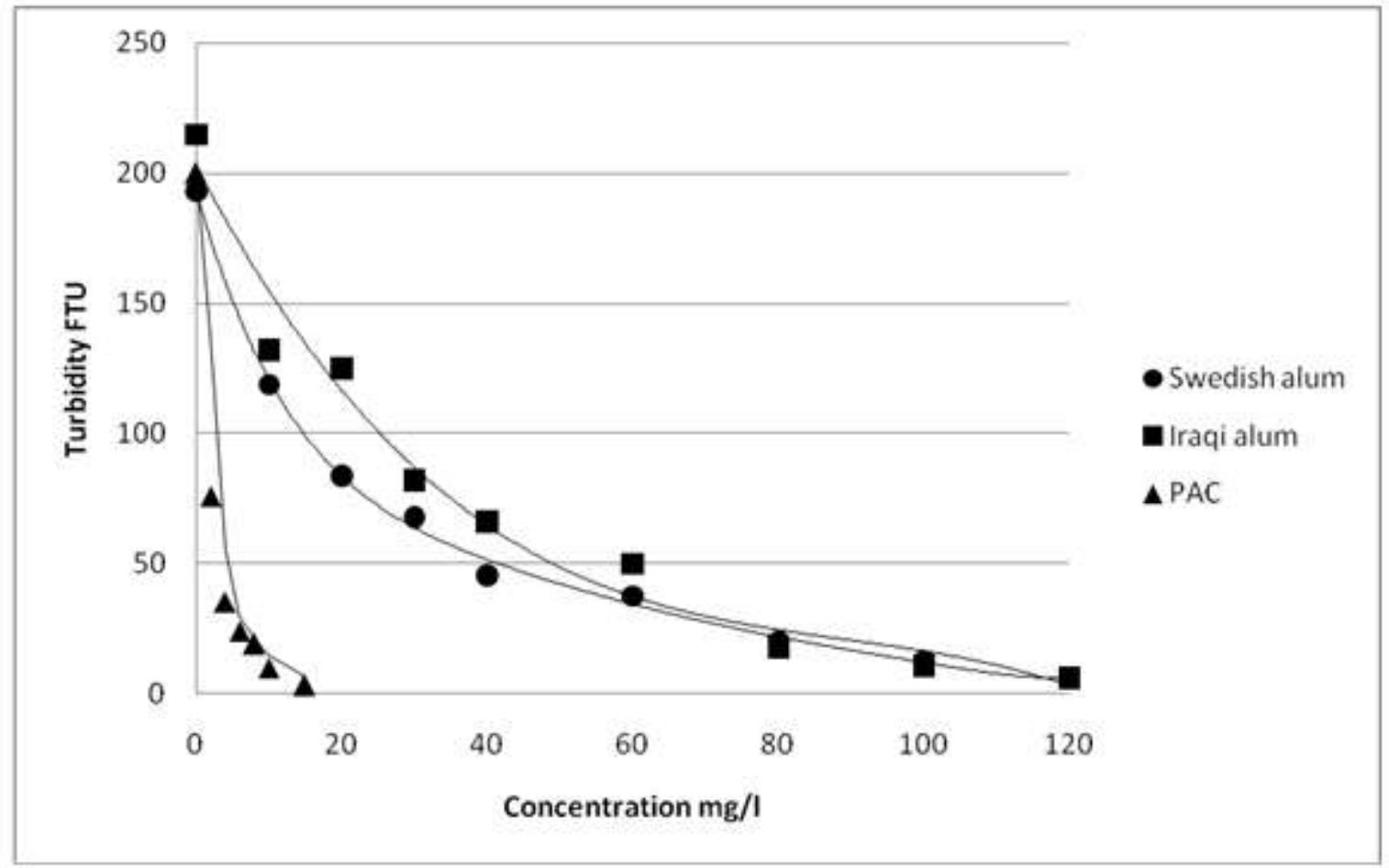

Figure 5. Relation betwen residual turbidity and coagulant concentration at 800 FTU level 
Table 2. Concentration of coagulats to produce water at FTU $=16$

\begin{tabular}{lcccc}
\hline $\mathrm{mg} / \mathrm{FTU}=30$ & $\mathrm{FTU}=150$ & $\mathrm{FTU}=550$ & $\mathrm{FTU}=800$ \\
\hline PAC & 0.25 & 0.3 & 8 & 8 \\
Swedish alum & 12.2 & 16 & 46.7 & 86 \\
Iraqi alum & 16 & 18 & 77 & 89 \\
\hline
\end{tabular}

aqua group by a hydroxyl group in the coordination sheath of a metal atom (as is present in alum) may render the complex more hydrophobic by reducing the interaction between the central metal atom and the remaining aqua groups, as can be observed in the following equations:

$$
\begin{aligned}
& \mathrm{Al}\left(\mathrm{H}_{2} \mathrm{O}\right)_{6}{ }^{++} \longrightarrow \mathrm{Al}\left(\mathrm{H}_{2} \mathrm{O}\right)_{5} \mathrm{OH}^{++}+\mathrm{H}^{+} \\
& \mathrm{Al}\left(\mathrm{H}_{2} \mathrm{O}\right)_{5}(\mathrm{OH})^{++} \longrightarrow \mathrm{Al}\left(\mathrm{H}_{2} \mathrm{O}\right)_{4}(\mathrm{OH})_{2}^{+}+\mathrm{H}^{+}
\end{aligned}
$$

This reduction in solvent-coagulant interaction might then, in turn, enhance the formation of covalent bonds between the metal atom and specific sites on the surface of the colloidal particle by reducing the energy necessary to displace water molecules from the coordination sheath. Finally, adsorption becomes especially pronounced in the PAC species because more than one hydroxide group per "molecule" can become attached at the interface (Stumm, Charles 1968).

\section{Conclusions}

The following conclusions can be drawn:

Based on the reaction between waste powder and hydrochloric acid, the laboratory-produced sample of PAC performed well in river water treatment. As compared to alum, an application of PAC yielded lower residual turbidity of treated water. Experimental results showed that the dosage of PAC required for river water treatment was $98 \%$ less as compared to alum at low turbidity, and required $90 \%$ less at higher levels of turbidity. Operation treatment using PAC gave excellent results as measured by rapid formation of flocs and compact sludge, and a shorter time for sedimentation. PAC also, has a wide range of dosage, and it may be well-suited to a wide range of turbidity. Thus, as compared to alum, it has better coagulation effects.

\section{References}

Alcoa World Chemicals (2001), Polyaluminum Chloride (PAC). [http://www.alumina.alcoa.com].

Al-Dawery S, Butris L (2002), Quality improvement of the locally produced alum. Iraqi J. of Chemical and Petroleum Engineering 3:50-58.

Alhadidi A, Kennedy M, Diepeveen A, Prummel H (2009), Scaling potential calculations using different methods. Desalination and Water Treatment 6:138-143.

ClearTech Industries Inc (2008), Drinking water treatment. Clear PAC-180 1327-41.

George S (1988), Basic water treatment for application world-wide. $2^{\text {nd }}$ ed, Thomas Telford, London $37-$ 51.

Halvadiya H, Gangadharan PK, Anand P (2008), Deionization of coagulated, clarified, turbid gauri shankar lake waters by using ion-exchange technology. Separation Science and Technology 43(8):2183-2195.

Kohlschutter HW, Hantelmann P, Diener K, Schilling H (1942), Basic aluminum chlorides. Zeitschr Anorg, Und allgemeine Chem. 248(4):319-344.

Mark JH (1975), Water and waste-water Technology. John Wiley \& Sons Inc. 270-455.

Stumm W, Charles RO (1968), Stoichiometry of coagulation. J. AWWA 60:514-539. 